\title{
Antisense Technology: An Emerging Platform for Cardiovascular Disease Therapeutics
}

\author{
Richard G. Lee • Jeff Crosby • Brenda F. Baker • \\ Mark J. Graham • Rosanne M. Crooke
}

Received: 15 May 2013 / Accepted: 21 June 2013 / Published online: 16 July 2013

(C) The Author(s) 2013. This article is published with open access at Springerlink.com

\begin{abstract}
Antisense oligonucleotides and small interfering RNAs, which suppress the translation of specific mRNA target proteins, are emerging as important therapeutic modalities for the treatment of cardiovascular disease. Over the last 25 years, the advances in all aspects of antisense technology, as well as a detailed understanding of the mechanism of action of antisense drugs, have enabled their use as therapeutic agents. These advancements culminated in the FDA approval of the first chronically administered cardiovascular antisense therapeutic, mipomersen, which targets hepatic apolipoprotein B mRNA. This review provides a brief history of antisense technology, highlights the progression of mipomersen from preclinical studies to multiple Phase III registration trials, and gives an update on the status of other cardiovascular antisense therapeutics currently in the clinic.
\end{abstract}

Keywords Antisense oligonucleotides $\cdot$ Small interfering RNAs · Apolipoprotein B · Atherosclerosis · Dyslipidemia · Coagulation $\cdot$ Thrombosis

\section{Introduction}

Antisense oligonucleotides (ASOs) are highly selective therapeutics that have demonstrated broad in vitro and in vivo activities and produced clinical benefit based upon a concept originally proposed in 1978 [1]. These drugs are short (1220-mer) nucleic acid sequences that bind, via Watson-Crick hybridization, to their complementary RNA substrates, which are their receptors. Upon hybridization, ASOs inactivate RNA

Associate Editor Enrique Lara-Pezzi oversaw the review of this article

R. G. Lee $(\triangle) \cdot$ J. Crosby • B. F. Baker • M. J. Graham •

R. M. Crooke

Isis Pharmaceuticals, Inc., 2855 Gazelle Court,

Carlsbad, CA 92010, USA

e-mail: rlee@isisph.com via two predominant termination mechanisms: (1) occupancy only, in which the binding of the ASO leads to translational arrest, inhibition of splicing, or induction of alternatively spliced variants, or (2) occupancy-induced destabilization, in which the RNA/DNA duplex is recognized and degraded by ribonuclease H1 (RNase H1), a ubiquitously expressed cellular endonuclease [2]. ASOs employing the RNase H pathway are widely used in the clinical setting, and this destabilization mechanism is utilized by all of the ASOs featured in this review.

The evolution of antisense technology from a simple cellfree experiment to a bona fide therapeutic platform was not trivial. For example, unmodified phosphodiester DNA ASOs had little therapeutic benefit due to their short half-lives, poor tissue distribution, and low affinity for RNA targets. Therefore, one of the initial steps that led to significant improvements in the pharmacology of ASOs was the replacement of the native phosphates in the backbone, which are highly sensitive to plasma and tissue exo- and endonucleases, with phosphorothioates (PSs) [3]. While the PS modification significantly improved stability and tissue distribution by enhancing plasma protein binding and prolonging tissue half-lives (1-3 days), the addition of the sulfur also tended to increase ASO pro-inflammatory properties. Second-generation ASOs involved altering the sugar moiety (see Fig. 1), with the most well characterized incorporating a methoxyethyl to the 2 ' position ( $\left.2^{\prime}-\mathrm{MOE}\right)$ or, alternatively, by tethering of the $4^{\prime}$-carbon to the $2^{\prime}$-hydroxyl of the ribose ring to create the bicyclic locked nucleic acid (LNA). These changes increased the melting temperatures of the RNA/ASO duplexes by $2-5{ }^{\circ} \mathrm{C} / \mathrm{mod}-$ ification and resulted in an increased affinity for the RNA substrate $[2,4,5]$. In addition, the proximity of the $2^{\prime}$ modification to the 3 '-phosphate likely created a steric hindrance that improved nuclease resistance [6] and altered non-specific protein binding, thus markedly reducing the pro-inflammatory properties of the ASOs [7]. Unfortunately, when added uniformly, both sugar modifications also made the ASO/RNA 
Fig. 1 Overview of ASO modifications. a Chemical structure of the 2'4'-locked nucleic acid (LNA) and the 2'-Omethoxyethyl RNA $(M O E)$. b Schematic of the gapmer ASO design. In order to facilitate RNase $\mathrm{H}$ activity, unmodified DNA is included in the internal, typically ten, nucleotides ("the gap"). The gap is flanked on the $5^{\prime}$ and $3^{\prime}$ ends with two to five of the MOE/ LNA-modified nucleotides, which enhances ASO stability and affinity for the target RNA a
2',4'-Locked Nucleic Acid (LNA)

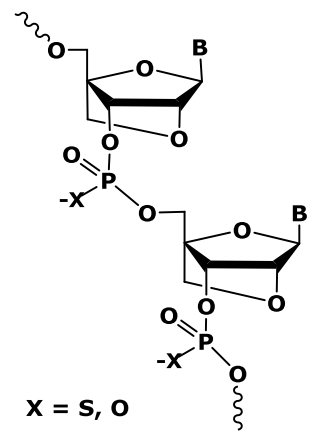

2'-O-Methoxyethyl RNA (MOE)

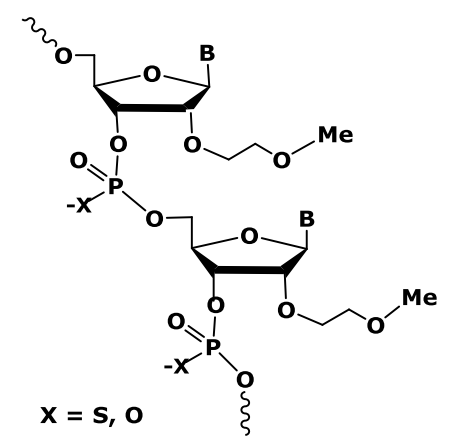

b

Gapmer ASO Design

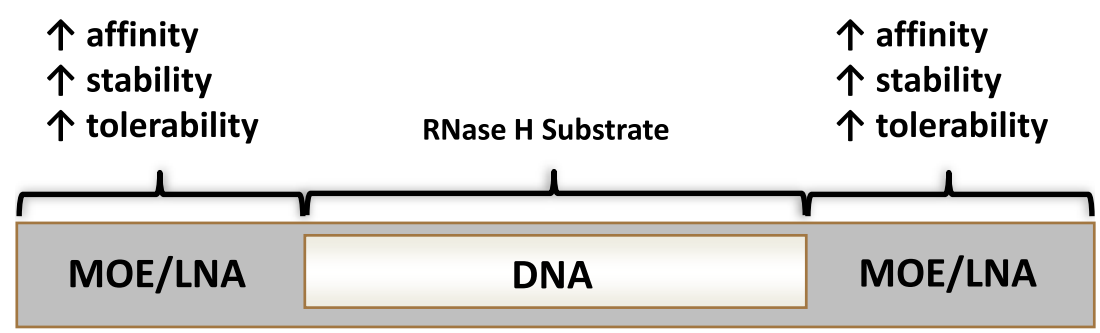

target duplex a poor substrate for the RNase H enzyme. To circumvent this, a "gapmer" design was implemented (see Fig. 1), in which the flanking regions of the ASO contain the 2 -MOE or LNA modifications while the center of the compound maintains unmodified sugars that serve as suitable substrates for RNase H-mediated cleavage [8].

With the enhanced stability, increase in potency, and reductions in non-specific toxicities, second-generation ASOs ( $2^{\prime}$-MOE gapmers) have been widely used in vivo. Since these drugs are readily soluble in saline, they can be administered without special formulation by multiple routes (subcutaneous, intravenous, intravitreal, topical, aerosol, oral, or enema) [9]. Tissue distribution of parenterally administered ASOs, which has been characterized extensively in preclinical models, is predominantly within the liver, kidney, and spleen with lesser distribution observed in the heart, ovaries, pancreas, testes, and uterus [10,11]. ASOs accumulate in cells through either a non-productive pathway, resulting in accumulation of drug into lysosomes, or a productive, endocytotic process whereby the drug gains access to the target mRNA [9]. Tissue half-lives of 2'-MOE gapmers range from 10 to 30 days, and typically, reductions in mRNA and protein in animal models can be observed as early as $24-48 \mathrm{~h}$ after initial dosing, with maximal efficacy occurring after 1 month of repeated administration [12]. In general, second-generation drugs have an attractive safety profile, both preclinically and in the clinic. The most commonly reported adverse events are transient injection site reactions, which are characterized by mild to moderate erythema, and flu-like symptoms [13].

Small interfering RNA (siRNA) represents another antisense mechanism used to reduce target mRNA expression [14]. SiRNAs are delivered as a duplex to the RNA-induced silencing complex (RISC), which contains several proteins including Argonaute 2 (Ago2), another cellular endonuclease. Ago 2 cleaves the siRNA duplex into a guide and a passenger strand, while the RISC complex retains the guide strand and releases the passenger strand [15]. The RISC/guide strand forms a haloenzyme which can then bind its single-strand mRNA complement and cleave via an Ago2-mediated process [16]. Due to their inherent chemical properties, siRNAs must be formulated with lipid conjugates or nanoparticles for effective in vivo drug delivery [17].

Finally, another antisense approach uses the microRNA (miRNA) pathway. MiRNAs are endogenous non-coding RNAs, approximately 22 nucleotides in length, that posttranscriptionally regulate numerous cellular and metabolic pathways [18]. Two strategies have evolved to alter miRNA activity, the first using synthetic mimicry of naturally occurring miRNAs, while the second blocks activity via complementary ASO inhibitors [19]. However, this relatively new antisense approach is still in preclinical development and will not be discussed in this review.

ASOs have been successfully used for a variety of disease states, including cancer [20-22], viral infection [23], insulin 
resistance [24, 25], neurological/neuromuscular diseases $[26,27]$, inflammatory diseases [7], and ocular diseases $[28,29]$. However, this review will primarily focus on the clinical successes of ASOs in cardiovascular disease.

\section{Kynamro}

The most advanced antisense drug is mipomersen sodium (trade name Kynamro, Table 1), a second-generation 2'-MOE gapmer ASO that targets the messenger RNA (mRNA) of apolipoprotein B (apoB) [30]. ApoB is the main structural component of the atherogenic lipoproteins VLDL, IDL, and LDL, collectively referred to as non-high-density lipoprotein (non-HDL). It is well established that plasma apoB, LDL cholesterol (LDL-C), and non-HDL cholesterol (non-HDL-C) are positively associated with coronary heart disease [31]. While the HMG-CoA reductase small molecule inhibitors (statins) have proven to be invaluable drugs for lowering LDL-C in the general population, there are still a significant number of patients at high risk for a cardiovascular event due, in part to, the inability to achieve their target LDL-C concentrations [32]. Familial hypercholesterolemic (FH) patients are at greatest risk, due to mutations in their LDL receptor which render them unable to clear plasma apoB-containing lipoproteins, resulting in markedly elevated plasma non-HDL-C concentrations and early onset of coronary heart disease (CHD) [33]. Because raising LDL receptor levels is the primary mechanism by which statins reduce circulating LDL-C, the efficacy of these drugs in the FH patient population has been limited [34]. Therefore, apoB represents an attractive molecular target for the antisense technology as (1) it is primarily expressed in the liver and (2) it does not possess enzymatic activity, making it "undruggable" by traditional small molecule inhibitors. In addition, since mipomersen inhibits apoB lipoprotein particle production and not LDL receptor clearance, it was initially hypothesized that administration of the drug would be useful in treating the high-risk FH patient population. Based upon these attributes, as well as positive clinical efficacy data, acceptable safety, and tolerability in preclinical models and in patients, the development of mipomersen by Isis Pharmaceuticals and Genzyme, a Sanofi Company, ultimately led to FDA approval for its use as an adjunct to lipid-lowering medications and diet to reduce LDL-C, apoB, total cholesterol, and nonHDL-C in patients with homozygous FH [35].

In preclinical studies, mice administered a murine apoB ASO produced dose-dependent reductions in hepatic apoB mRNA and protein, and concurrent reductions in plasma apoB, cholesterol, and LDL-C [36]. Subsequent studies in lowdensity lipoprotein receptor (LDLR) $-/-$ mice demonstrated expected suppression of atherogenic lipoproteins with concomitant dose-dependent reductions in aortic atherosclerosis [37]. Interestingly, despite reducing VLDL secretion, an event that could potentially lead to hepatic triglyceride (TG) accumulation, chronic administration of the murine apoB ASO did not produce such changes [36-38]. While the precise underlying mechanisms are still under investigation, it was shown in part to be due to the up-regulation of fatty acid oxidation and downregulation of lipogenic genes such as sterol response element binding protein 1-c (SREBP1-c), acetyl-CoA carboxylase 1, and hepatic fatty acid synthase (FASN) with a tendency to suppress hepatic fatty acid synthesis. This observation was also made in mice harboring the apoB 38.9 truncation [39]. Further preclinical studies demonstrated that, much like mice, administration of the apoB ASO to rats, hamsters, rabbits, and monkeys led to reductions in hepatic apoB mRNA and protein, and concomitant reduction in plasma apoB, cholesterol, and LDL-C [30]. In addition, transcriptional profiling of livers from monkeys administered a monkey apoB ASO demonstrated similar reductions in lipogenic genes such as SREBP1-c and FASN.

Table 1 Summary of antisense drugs approved or in clinical trials

\begin{tabular}{|c|c|c|c|}
\hline Drug name & Drug target & Cardiovascular effect & Current status \\
\hline Kynamro & Apolipoprotein B & $\begin{array}{l}\text { Lowers plasma apoB, TPC, LDL-C, } \\
\text { non-HDL-C, and Lp(a) }\end{array}$ & $\begin{array}{l}\text { FDA approval for its use as an adjunct to lipid-lowering } \\
\text { medications for homozygous FH patients }\end{array}$ \\
\hline SPC4955 & Apolipoprotein B & $\begin{array}{l}\text { Lowers plasma apoB, TPC, LDL-C, } \\
\text { non-HDL-C, and Lp(a) }\end{array}$ & Phase I (completed) \\
\hline ApoC-III $I_{R x}$ & Apolipoprotein C-III & Lowers plasma apoC-III and TG & Phase I (completed), Phase II initiated \\
\hline $\mathrm{FXI}_{\mathrm{Rx}}$ & Factor XI & Prevents thrombosis & Phase I (completed) \\
\hline BMS-844421 & PCSK9 & $\begin{array}{l}\text { Lowers plasma apoB, TPC, LDL-C, } \\
\text { and non-HDL-C }\end{array}$ & Phase I (terminated) \\
\hline SPC5001 & PCSK9 & $\begin{array}{l}\text { Lowers plasma apoB, TPC, LDL-C, } \\
\text { and non-HDL-C }\end{array}$ & Phase I (terminated) \\
\hline ALN-PCS02 & PCSK9 & $\begin{array}{l}\text { Lowers plasma apoB, TPC, LDL-C, } \\
\text { and non-HDL-C }\end{array}$ & Phase I (completed) \\
\hline $\mathrm{ApoA}_{\mathrm{Rx}}$ & Apolipoprotein(a) & Lowers $\operatorname{Lp}(\mathrm{a})$ & Phase I initiated \\
\hline
\end{tabular}

TPC total plasma cholesterol 
Consistent with these compensatory effects, the monkeys, like the mice, did not develop hepatic steatosis.

In the first short-term placebo-controlled, double-blind, doseescalation Phase I trial [40], subcutaneous (SC) administration of mipomersen to healthy volunteers was efficacious. Dosedependent reductions occurred in both apoB and LDL-C levels relative to baseline, with the 200-mg dose of mipomersen producing a maximum apoB reduction of $50 \%$ and a maximum LDL-C reduction of $35 \%$. The observed pharmacology correlated with drug exposure as estimated by the area under the curve for drug plasma trough levels. In subjects who received the 200-mg dose, the drug's terminal elimination half-life was approximately 30 days. This durability was reflected by prolonged pharmacology, where apoB and LDL-C levels remained below baseline for 3 months after treatment in most subjects (six of eight) of the $200 \mathrm{mg}$ dose group. No significant changes occurred in HDL-C levels across all dose groups.

In a second Phase I trial designed to evaluate clinical pharmacokinetics, mipomersen was coadministered with either simvastatin, an HMG-CoA reductase inhibitor, or ezetimibe, a drug that blocks cholesterol absorption [41]. The results from this study demonstrated no clinically relevant pharmacokinetic interactions between mipomersen and the other dyslipidemia agents. Further to these results, in vitro assays demonstrated no effect of mipomersen on cytochrome P450 activity or P-glycoprotein.

Several short-term randomized, placebo-controlled, doseescalation Phase II trials were performed where mipomersen was evaluated as a single agent [42] and as an add-on to stable lipid-lowering therapy $[43,44]$ in subjects with varying degrees of hyperlipidemia. As a monotherapy, mipomersen produced reductions from baseline of -7 to $-71 \%$ in LDL-C after 13 weeks of dosing at 50 to $400 \mathrm{mg} / \mathrm{week}$, respectively. A large proportion of subjects who received $\geq 200 \mathrm{mg} /$ week mipomersen (19 of 24) achieved LDL-C levels below 2.6 $\mathrm{mmol} / \mathrm{L}(100 \mathrm{mg} / \mathrm{dL})$, where the mean baseline level of mipomersen-treated subjects was $4.5 \mathrm{mmol} / \mathrm{L}(170 \mathrm{mg} / \mathrm{dL})$. Parallel dose-dependent reductions occurred in apoB and nonHDL-C. Indeed, half of the subjects who received the highest dose of $400 \mathrm{mg} /$ week mipomersen achieved apoB levels at or below the limit of detection of $35 \mathrm{~g} / \mathrm{L}$ by week 12 .

A similar profile was observed when mipomersen treatment was added to ongoing stable statin therapy [43]. In a 5week dose-escalation Phase II study, subjects who received the 200-mg dose of mipomersen had a significant mean reduction in LDL-C of $-27 \%$ from baseline while the 400 $\mathrm{mg}$ dose resulted to a mean reduction of $-38 \%$. Parallel reductions occurred in apoB and non-HDL-C. In a separate cohort, administration of mipomersen $(200 \mathrm{mg})$ weekly led to $36 \%$ reduction in both apoB and LDL-C from baseline after 13 weeks of treatment.

A third dose-escalation Phase II trial involved subjects diagnosed with heterozygous FH on stable lipid-lowering therapy who received 50 to $300 \mathrm{mg} /$ week mipomersen, or placebo, over a 6 -week treatment period [44]. In this study population, LDL-C was significantly reduced from baseline compared to pooled placebo in the 200 and $300 \mathrm{mg} /$ week dose groups by -21 and $-34 \%$, respectively, with concordant dose-dependent reductions in apoB, non-HDL-C, and total cholesterol. Subjects assigned to the $300 \mathrm{mg} / \mathrm{week}$ cohort continued once-weekly dosing for an additional 7 weeks to achieve a mean reduction of $-37 \%$ in LDL-C and apoB from baseline, 1 week after the last dose.

Overall, mipomersen was well tolerated in each of the three short-term Phase II trials. The most common adverse event reported was injection site reactions (ISRs), a common side effect of subcutaneously administered drugs [45-47]. Elevations in liver transaminases, which were reversible upon continued dosing or once the drug was discontinued, occurred in a limited number of subjects treated with mipomersen at doses of $200 \mathrm{mg}$ or higher. These elevations were asymptomatic and not accompanied by abnormalities in other measures of liver function, such as total bilirubin, albumin, and prothrombin. There were no clinically relevant changes or treatment effects in other safety and laboratory assessments, such as vital signs, electrocardiograms, renal function tests, coagulation, and urinalyses.

Three 26-week randomized, placebo-controlled Phase III trials that enrolled $\mathrm{FH}$ patients with a range of risk and severity of cardiovascular disease were also conducted [48-50]. The first trial evaluated the effects of mipomersen in patients with the most severe form of this genetic disease, homozygous FH [48]. Homozygous FH patients on stable low-fat diets and maximally tolerated lipid-lowering therapy (LLT) were administered once-weekly SC doses of either mipomersen $(200 \mathrm{mg})(n=34)$ or placebo $(n=17)$ for 26 weeks. Dose adjustments were not permitted. The mean age was 31 years, and 44 of 51 patients $(86 \%)$ were taking the maximum dose of a statin or other LLT. Two weeks following the final dose, patients who received mipomersen showed a significant mean reduction in plasma LDL-C $(-25$ vs. $-3 \%$ placebo, $p=0.0003$ ) from a mean baseline level of $11.4 \mathrm{mmol} / \mathrm{L}$ (440 mg/dL). This response corresponded to a mean absolute reduction of $-2.9 \mathrm{mmol} / \mathrm{L}(-113 \mathrm{mg} / \mathrm{dL})$ in LDL-C. Furthermore, plasma apoB levels decreased by a significant amount relative to baseline ( -27 vs. $-3 \%$ placebo, $p<0.0001)$. Notably, a significant increase in HDL-C levels from baseline occurred in mipomersen-treated patients ( +15 vs. $+4 \%$ placebo, $p=0.03$ ).

The second Phase III trial involved heterozygous FH patients with stable coronary artery disease [49]. Patients were administered either mipomersen $(200 \mathrm{mg})(n=83)$ or placebo $(n=41)$ once weekly (SC administration) for 26 weeks as an add-on to ongoing maximum tolerated dose of a statin and stable LLT. The mean age was 56 years, and 81 of 124 patients $(65 \%)$ were taking the maximum dose of a 
statin. Two weeks following the final dose, patients who received mipomersen experienced a significant reduction in plasma LDL-C ( -28 vs. $+5.2 \%$ placebo, $p<0.001)$ from a mean baseline level of $4.0 \mathrm{mmol} / \mathrm{L}(153 \mathrm{mg} / \mathrm{dL})$. This response corresponded to a mean absolute reduction of -1.3 $\mathrm{mmol} / \mathrm{L}(-49 \mathrm{mg} / \mathrm{dL})$ in LDL-C. ApoB also decreased by a significant amount relative to baseline $(-26$ vs. $+7 \%$ placebo, $p<0.001)$, as did other apoB-containing lipoproteins such as non-HDL-C and lipoprotein (a) (Lp(a)). Assessment of liver TG content by magnetic resonance imaging at baseline and end of treatment showed a median increase in liver fat content of $+4.9 \%$ in mipomersen-treated patients, compared to $+0.4 \%$ in placebo.

The third Phase III trial evaluated mipomersen in patients with severe hypercholesterolemia (HC). Severe HC was defined as LDL-C greater than or equal to $7.8 \mathrm{mmol} / \mathrm{L}$ (300 $\mathrm{mg} / \mathrm{dL})$, or $\mathrm{LDL}-\mathrm{C} \geq 5.1 \mathrm{mmol} / \mathrm{L}(200 \mathrm{mg} / \mathrm{dL})$ with preexisting $\mathrm{CHD}$, while on a maximum tolerated statin dose and stable LLT [50]. Patients were administered onceweekly SC doses of either mipomersen $(200 \mathrm{mg})(n=39)$ or placebo $(n=19)$ for 26 weeks as an add-on to ongoing therapy. The mean age was 51 years, and 24 of 58 patients (41\%) were taking a maximum statin dose. Two weeks following the final dose, patients who received mipomersen experienced a significant reduction in plasma LDL-C $(-36$ vs. $+13 \%$ placebo, $p<0.001)$ from a mean baseline level of $7.2 \mathrm{mmol} / \mathrm{L}(276 \mathrm{mg} / \mathrm{dL})$. This response corresponded to a mean absolute reduction of $-2.6 \mathrm{mmol} / \mathrm{L}(-101 \mathrm{mg} / \mathrm{dL})$ in LDL-C. ApoB decreased to a similar extent relative to baseline $(-36$ vs. $+11 \%$ placebo, $p<0.001)$.

Mipomersen has also been evaluated for safety and efficacy in two other high-risk CHD populations based on the same study design as the aforementioned Phase III trials [51, 52]. One was a Phase III trial that involved patients at high risk for CHD and with LDL-C levels greater than or equal to 2.6 $\mathrm{mmol} / \mathrm{L}(100 \mathrm{mg} / \mathrm{dL})$ despite treatment with a maximum tolerated statin dose and LLT [52]. In this study, 88 of 153 randomized patients ( $56 \%$ ) were type 2 diabetics. The other 26-week placebo-controlled trial involved subjects with uncontrolled LDL-C levels $(\geq 3.4 \mathrm{mmol} / \mathrm{L})$ who were intolerant to statins [51]. Nearly half of the subjects (15 of 33) in this study were not taking lipid-lowering medications. Mipomersen produced robust reductions in LDL-C from baseline compared to placebo in both study populations, with a mean percentage change from baseline of $-37 \%$ (vs. $-5 \%$ placebo, $p<0.001$ ) and $-47 \%$ (vs. $-2 \%$ placebo, $p<0.001$ ) 2 weeks after the last dose, respectively. Concordant reductions occurred in all apoBcontaining lipoproteins tested, including non-HDL-C and Lp(a).

No new safety concerns emerged in the Phase III trials. Consistent with previous studies, the most common side effects experienced by patients were ISRs and flu-like symptoms. A limited number of patients also experienced persistent elevations in liver transaminase levels. These increases were not accompanied by abnormalities in other measures of liver function, were largely reversible with continued treatment or otherwise, and receded back to baseline values in post-dose follow-up. Beyond these findings, no additional safety issues have been identified in the corresponding Phase III open-label extension trial [53]. Notably, increases in liver fat content have tended to stabilize or decrease after 1 year of treatment in patients participating in the Phase III extension. This trend may reflect compensatory changes in hepatic lipid metabolism first observed in the preclinical animal model studies.

As described above, mipomersen has been approved by the FDA for use as an adjunct to first-line therapies in homozygous FH patients to reduce LDL-C, non-HDL-C, apoB, and total cholesterol. Another randomized, doubleblind, placebo-controlled Phase III trial is currently in progress to assess the safety and efficacy of an alternative lower and more frequent dose regimen and the approved 200-mg weekly dose regimen in patients with severe FH [6]. The estimated study completion date is late 2014. Positive safety and efficacy data will further support consideration of mipomersen for use as an adjunct to existing therapies in other high-risk patient populations.

In addition to mipomersen, both siRNA and LNA oligonucleotides targeting apoB mRNA have been studied [54, 55]. Currently, the siRNA has only been evaluated in rodents and non-human primates, but at the time of this publication had not advanced into clinical trials. A multiple-ascendingdose Phase I clinical trial in 18 healthy subjects with the apoB LNA (SPC4955) was completed in November 2011, but at present, the outcome of the trial has not been disclosed [56], nor have any other clinical trials been initiated.

\section{ISIS-APOCIII $_{R x}$}

Hypertriglyceridemia (HTG) is an independent risk factor for cardiovascular disease [57] and pancreatitis [58, 59]. Furthermore, it has been shown that reducing plasma TG below $5.7 \mathrm{mmol} / \mathrm{L}(500 \mathrm{mg} / \mathrm{dL})$ in severe HTG patients had both clinical and economic benefits [60].

Apolipoprotein C-III (apoC-III) is an important regulatory factor in plasma TG homeostasis. It is a 79-amino acid glycoprotein that is present on all lipoprotein classes, with the majority found on HDL particles (60\% of total plasma apoC-III) and less on the apoB-containing lipoprotein particles $(20,10$, and $10 \%$ of total plasma [61] apoC-III is found on VLDL, IDL, and LDL, respectively) [62]. Studies in animal models and humans indicate that apoC-III affects plasma TG catabolism. In mice, over-expression of apoCIII leads to marked HTG [63, 64], while genetic knockout results in reductions in plasma TG $[65,66]$. The importance of apoC-III was highlighted in an Old World Amish 
population where a heterozygous loss-of-function allele for $A P O C 3$ resulted in significantly reduced plasma $\mathrm{TG}$ and LDL-C, as well as increased HDL-C [67]. In contrast, it was found that gain-of-function mutations in the $A P O C 3$ promoter in an Asian Indian population led to significantly increased fasting plasma TG levels [68]. While the exact mechanism by which apoC-III exerts its effects is unclear, there is evidence that it may act directly by inhibiting lipoprotein lipase [69], reducing clearance of TG-rich lipoproteins [70], and enhancing hepatic TG secretion [71]. However, the relative contribution of each of these pathways is uncertain.

Analysis of the Cholesterol and Recurrent Events trial showed that in a model which adjusted for LDL-C, VLDL$\mathrm{C}$, TG, and HDL-C, apoC-III VLDL+LDL remained an independent risk factor for a recurrent event [72], indicating that the pro-atherogenic properties of apoC-III extend beyond its role in TG metabolism. Subsequent studies have shown that apoCIII found on apoB-containing particles has pro-inflammatory properties via enhancing adhesion of monocytic cells to endothelial cells [73] and downstream induction of endothelial cell vascular cell adhesion molecule I [74].

In addition to its pro-atherogenic effects, elevated plasma apoC-III concentrations have also been implicated in the development of insulin resistance and diabetes in both preclinical and human epidemiology studies. ApoC-III protein expression has been shown to be regulated by insulin [75] via a Foxo1-mediated process [76]. Indeed, dietarychallenged transgenic mice over-expressing human APOC 3 had significantly elevated insulin levels with no difference in glucose, indicating insulin resistance [64]. In humans, variants in an insulin response element of the $A P O C 3$ promoter led to loss of insulin-mediated apoC-III transcriptional regulation. This was later associated with an increased incidence of NAFLD and insulin resistance in an Asian Indian population [68]. However, this result was not replicated in a second study performed in an African-American population [77]. It is also interesting to note that a group of Ashkenazi Jews harboring a loss-of-function mutation in $A P O C 3$ that only lowered plasma apoC-III protein by $30 \%$ did not significantly change plasma $\mathrm{TG}$, but remained associated with improved insulin sensitivity, lower blood pressure, and increased longevity [78], further suggesting the involvement of apoC-III in multiple, complex metabolic pathways.

Due to the large body of evidence summarized above implicating apoC-III in cardiovascular and metabolic disease progression, apoC-III ASOs were developed targeting mouse, rat, monkey, and human transcripts [79]. In several mouse and rodent models, administration of apoC-III ASO led to significant dose-dependent reductions in apoC-III and concomitant significant reductions in plasma TG. Administration of apoCIII ASO to apoC3 $-/-$ mice had no effect on plasma TG, indicating that the TG-lowering effects of the apoC-III ASO were target specific. Hepatic TG secretion in apoC-III ASOtreated C57BL/6 mice receiving poloxamer 407 , which blocks apoB particle clearance allowing for quantitation of apoB secretion [80], was not different compared to that in controls, suggesting that the TG-lowering effects of the apoC-III ASO were due to changes in clearance, not hepatic secretion. Administration of apoC-III ASO to HTG rhesus monkeys also led to significant dose-dependent reductions in plasma apoCIII mRNA with subsequent reduction in plasma TG.

Due to significant and consistent TG-lowering effects in multiple preclinical species with no apparent tolerability issues, a Phase I clinical trial of the human apoC-III ASO (ISISAPOCIII $_{R x}$-ISIS 308401), a 5-10-5 MOE gapmer, was initiated. This double-blind, placebo-controlled, dose-escalation stud$\mathrm{y}$, in which patients were dosed for 4 weeks with 50, 100, 200, or $400 \mathrm{mg}$ of ISIS-APOCIII $\mathrm{Rx}_{\mathrm{x}}$, was performed in healthy human volunteers to assess safety, pharmacokinetics, and pharmacodynamics [79]. As observed in preclinical studies, administration of ISIS 308401 led to significant dose-dependent reductions in apoC-III protein with concomitant reductions in plasma TG $(-50 \%)$ relative to baseline at the highest administered dose. Reductions in plasma apoC-III protein and TG were seen as early as 8 days after the initial dose [79]. ISIS 308401 was generally well tolerated with no serious adverse events or early dosing terminations. Consistent with administration of other second-generation antisense drugs, the most common adverse events were ISRs. The successful completion of this Phase I trial in healthy human volunteers has since led to Phase II trials in subjects with very high TG levels [61] and those with moderately high TG levels and type 2 diabetes [81].

\section{ISIS-FXI $_{R x}$}

Precise control of the coagulation cascade at sites of vessel wall injury leads to thrombin production and the formation of a hemostatic plug. Patients with low levels of coagulation factor XI (FXI) have a reduced risk for thromboembolic diseases $[37,38]$ with no associated bleeding issues, demonstrating that FXI appears to play only a minor role in hemostasis $[82,83]$. Increased FXI levels in patients may result in increased risk of venous thrombosis, myocardial infarction, and stroke [84, 85]. Further, several preclinical studies demonstrating the importance of FXI in thrombosis [86-91], with minimal contribution to hemostasis, validate FXI as an attractive pharmacological target.

To further characterize the role of coagulation factors in thrombosis, mouse-specific ASOs were developed to specifically deplete the expression of individual coagulation factors. Mouse studies utilizing FXI-specific ASOs demonstrated that inhibition of FXI mRNA in the liver led to reduced levels of plasma FXI protein and activity [92]. The measured anticoagulant effect after ASO depletion of FXI resulted in a 
dose-dependent prolongation of activated partial thromboplastin time (aPTT) with no effect on prothrombin time. The treatment of mice with FXI ASOs resulted in antithrombotic effects in the $\mathrm{FeCl}_{3}$-induced IVC thrombosis model with no increased bleeding. The use of warfarin in that study was effective at reducing thrombosis, but increased bleeding. FXI ASO treatment was also effective at reducing thrombosis in a mesenteric vein and stenosis-induced mouse model without increased bleeding [92]. To determine the safety and effectiveness of FXI ASOs in combination with standard of care agents, studies were carried out with either an anticoagulant $\left(\right.$ Lovenox ${ }^{\circledR}$ ) or an antiplatelet drug $\left(\right.$ Plavix $\left.^{\circledR}\right)$. Results from these experiments demonstrated increased antithrombotic activity without enhancement in bleeding risk [92].

To evaluate the safety and pharmacodynamic profile of FXI ASOs in primates, the drug was subcutaneously administered for 13 weeks in cynomolgus monkeys [93]. Those results demonstrated a dose-dependent reduction of FXI mRNA level in the liver and plasma with a corresponding increase in aPTT. The potential for increased bleeding after FXI inhibition was examined in tissues of high fibrinolytic activity using surgical models (oral mucosa and partial tail amputation) in addition to tissues with low intrinsic fibrinolytic activity (skin laceration). A $70 \%$ reduction in plasma FXI activity after FXI ASO treatment resulted in no enhancement in bleeding time or blood volume loss, while enoxaparin treatment increased both endpoint measurements [93].

Patients with severe FXI deficiency have reduced risk for thrombosis, and baboons treated with a monoclonal antibody (Mab) against FXI, which reduces FXI levels in plasma by $99 \%$, have reduced thrombosis in a well-characterized baboon model of thrombosis and hemostasis [88]. Importantly, no increased bleeding was observed with almost complete inhibition of FXI in these monkeys. To define anticoagulation and antithrombotic activity that might ultimately be achieved in clinical applications in humans, the minimal level of FXI reduction in primates required to achieve antithrombotic activity was assessed in a baboon model of thrombosis and hemostasis [94]. First, the FXI Mab was titrated in these animals to estimate the level of FXI required for antithrombotic activity followed by administration of FXI ASOs until the estimated antithrombotic levels were achieved. An intravenous injection of FXI Mab inhibited both FXI plasma activity and platelet deposition in a propagating thrombus by $50 \%$ [94]. The FXI ASO was then administered by subcutaneous injection three times per week at a dose of $25 \mathrm{mg} / \mathrm{kg}$, reducing FXI protein and activity levels by $50 \%$ while increasing aPTT. Further, when FXI plasma levels were reduced to less than $50 \%$ of the normal, thrombin generation was almost completely abolished [94]. Finally, ASO reduction of FXI plasma levels did not increase bleeding in baboons.

The safety, tolerability, and pharmacodynamics of ISIS$\mathrm{FXI}_{\mathrm{Rx}}$ were evaluated in a double-blind, ascending-dose, placebo-controlled Phase I study in healthy subjects after a 6-week treatment period. Treatment with ISIS-FXI $\mathrm{R}_{\mathrm{Rx}}$ demonstrated a robust, sustained, and dose-dependent reduction in FXI protein and activity that was accompanied by a concomitant increase in aPTT [95]. No study drug-related bleeding events were reported even in subjects in whom plasma FXI activity levels were reduced to undetectable levels. ISIS$\mathrm{FXI}_{\mathrm{Rx}}$ did not cause clinically significant changes in vital signs, ECG, hepatic function, renal function, or hematology. These data are consistent with preclinical data obtained in multiple species and provide support for development of ISIS-FXI $I_{R x}$ as a novel approach for the treatment and prevention of thromboembolic disorders.

\section{PCSK9}

Proprotein convertase subtilisin/kexin type 9 (PCSK9) is a member of the proprotein convertase family of proteases. Epidemiological studies have suggested that loss-of-function mutations in PCSK9 result in lifelong reductions in LDL-C that are associated with significant reductions in the incidence of coronary heart disease [96-99]. Pcsk9-deficient mice exhibited twofold increases in hepatic LDLRs and significant reductions in LDL via enhanced hepatic clearance [96]. The binding site of PCSK9 to the LDLRs was identified as the first epidermal growth factor-like repeat (EGF-A) in the EGF homology domain [97]. PCSK9 binding to EGF-A appears to interfere with a conformational change required for receptor turnover, effectively shunting LDLRs from recycling to degradation fates.

Intraperitoneal administration of a murine-specific PCSK9 2'-MOE-modified ASO (ISIS 394814) to high fat-fed mice for 6 weeks reduced total cholesterol and LDL-C by -53 and $38 \%$, respectively, and produced a twofold increase in liver LDLR protein concentrations [100]. Further, ISIS 394814 produced hepatic PCSK 9 mRNA reductions of $92 \%$ vs. saline after 6 weeks of treatment. To demonstrate that the LDL lowering produced by the PCSK9 ASO required functional LDL receptors, studies were also performed in $L d l r$-deficient mice treated with ASO for 6 weeks at $50 \mathrm{mg} / \mathrm{kg} /$ week. As anticipated, in mice genetically lacking LDLR, no reduction in plasma lipid levels was observed. Based upon these positive effects in multiple mouse models, high-density screens were performed in human hepatoma cell lines to identify an optimal human PCSK9 ASO inhibitor. A subsequent Phase I clinical trial was conducted evaluating a 2'-MOE-modified human PCSK9 ASO (BMS-844421) but was terminated by BristolMyers Squibb in January 2011 [101].

A similar lipid-lowering profile was also observed testing a LNA-modified ASO after IV administration in mice [102]. Based upon those compelling preclinical findings with the (LNA) ASO, Santaris Pharma A/S initiated a Phase I clinical 
trial in May 2011 evaluating SPC5001, an optimized human PCSK9 compound [103]. This trial was also terminated in November 2011. A recent publication revealed that SPC5001 produced acute renal injury in a single subject following three weekly doses of $5 \mathrm{mg} / \mathrm{kg}$ on days 1,8 , and 15 [104].

Researchers at Alnylam developed active, cross-species siRNAs capable of targeting PCSK9 expression in rodents, non-human primates, and humans. For in vivo studies, PCSK9 and control siRNAs were formulated in lipidoid nanoparticles. Liver-specific siRNA silencing of PCSK9 in mice and rats reduced PCSK9 mRNA levels by 50-70\% [105] with a concomitant $60 \%$ reduction in plasma total cholesterol concentrations. In PCSK9 transgenic mice, siRNAs suppressed the human PCSK9 transcript by $>70 \%$ while significantly reduced PCSK9 plasma protein levels. In a non-human primate study, a single dose of the PCSK9 siRNA targeting resulted in a rapid lowering of plasma PCSK9, apoB, and LDL, without affecting HDL or TG levels.

Alnylam initiated a randomized, single-blind, placebocontrolled, single-ascending-dose Phase I study in healthy volunteers with elevated LDL-C $>3 \mathrm{mmol} / \mathrm{L}(116 \mathrm{mg} / \mathrm{dL})$ in September 2011 [106]. As a monotherapy, ALN-PCS02 resulted in statistically meaningful and durable reductions of plasma PCSK9 of up to $84 \%$ and lowering of LDL-C of up to $50 \%$. Results following a single dose of ALN-PCS support a once-monthly dosing regimen. ALN-PCS02 was shown to be safe and well tolerated in this study, and there were no serious adverse events. An additional Phase I trial is underway to further evaluate ALN-PCS02, an intravenously administered siRNA, vs. ALN-PCSsc, a subcutaneously administered alternate formulation.

Currently the most advanced PCSK9 clinical inhibitors are humanized Mab. Both Regeneron (REGN727) and Amgen (AMG145) are conducting multiple Phase II/III trials where primary outcomes will be determined in tens of thousands of dyslipidemic subjects $[9,94]$. Results obtained from these ongoing clinical trials will ultimately determine the validity and safety of targeting PCSK9 as a lipid-lowering therapeutic approach.

\section{ISIS-APOA $_{\mathbf{R x}}$}

$\mathrm{Lp}(\mathrm{a})$ is a complex lipoprotein particle found in human plasma. Lp(a) consists of a LDL-like particle with apolipoprotein(a) (apo(a)) bound to the apoB protein via a disulfide bond. The apo(a) protein shows a high degree of homology to plasminogen at both the nucleotide and the amino acid level [107]. However, in humans, the apo(a) gene transcript is much larger due to a repetitive kringle IV domain in the $L P A$ gene. The majority of apo(a) mRNA is expressed in the liver, with minor amounts present in the testis, brain, adrenals, lung, and pituitary. Elevated $\mathrm{Lp}$ (a) levels are an independent risk factor for the development of cardiovascular disease, peripheral vascular, and cerebrovascular disease [108, 109]. Recently a genomewide association study identified a SNP in the LPA locus that was significantly associated with aortic valve calcification across several ethnic groups [110]. While extensive epidemiological evidence indicates that elevated plasma $L p(a)$ levels are pro-atherogenic [111], the molecular mechanisms by which it contributes to the atherosclerotic process remain enigmatic. There is evidence that apo(a) may impair fibrinolysis of thrombosis, accelerate macrophage foam cell formation [112], and act as a sink for oxidized phospholipids [113].

Due to the expanding evidence indicating that $\mathrm{Lp}$ (a) contributes to CAD, a human apo(a)-specific ASO was developed and characterized in three human LPA transgenic mouse models: (1) mice expressing a human $L P A$ construct (8K-LPA mouse) and (2) mice expressing human $A P O B$ and the human $L P A$ construct (8K-LPA and transgenic mice expressing the natural human apo(a) gene in a yeast artificial chromosome (12K-LPA)) [114]. Mice treated for 4 weeks showed significant reductions in hepatic apo(a) mRNA expression, with the ASO showing greater efficacy in the $12 \mathrm{~K}-L P A(87 \%$ reduction compared to saline) relative to the $8 \mathrm{~K}-L P A$ and in the $8 \mathrm{~K}$ $L P A$ (52\% reduction). In the $12 \mathrm{~K}-L P A$ mouse, apo(a) ASO treatment significantly reduced plasma apo(a) protein levels $(11,060 \pm 7,137$ vs. $76,983 \pm 14,598$ RLU at baseline) and OxPL/m-apoB $(9,965 \pm 907$ vs. $28,003 \pm 2,573 \mathrm{RLU}$ at baseline). These encouraging preclinical results provided the impetus to initiate a Phase I trial in March 2013 to assess the efficacy and safety of the $\mathrm{APOA}_{\mathrm{Rx}}$ in healthy human volunteers. Results from these ongoing trials will define the potential therapeutic benefit of reducing plasma apo(a) levels in dyslipidemic patients.

\section{Summary}

After more than 30 years of basic research and a significant investment in nucleic acid-based medicinal chemistry optimization, antisense technology has emerged as a third therapeutic platform, distinct from small molecule and proteinbased approaches, for the treatment of a wide variety of disease indications. Extensive preclinical research and clinical experience with second-generation ASOs have demonstrated that these drugs are safe and efficacious agents that can selectively reduce the expression of a wide variety of disease-associated proteins. Further, the inherent specificity of the ASO-mediated mRNA termination mechanism allows for precise isoform targeting, which has proven difficult with other drug classes. Mipomersen, the first systemic antisense drug approved by the FDA for the treatment of hypercholesterolemia in HoFH patients, represents the first of many other therapeutic opportunities in clinical development. In addition to dyslipidemia indications, ASOs targeting inflammation, 
cancer, coagulation, neurological diseases, metabolic syndrome, rare genetic disease, and splicing disorders are currently advancing in the clinic.

Acknowledgments We would like to thank Joe Johnston, Steve Hughes, and Sanjay Bhanot for the careful review of the manuscript and Punit Seth for providing illustrations for the figure.

Open Access This article is distributed under the terms of the Creative Commons Attribution License which permits any use, distribution, and reproduction in any medium, provided the original author(s) and the source are credited.

\section{References}

1. Stephenson, M. L., \& Zamecnik, P. C. (1978). Inhibition of Rous sarcoma viral RNA translation by a specific oligodeoxyribonucleotide. Proceedings of the National Academy of Sciences of the United States of America, 75(1), 285-288.

2. Crooke, S. T. (Ed.). (2001). Antisense drug technology: principles, strategies, and applications (1st ed.). New York: Marcel Dekker.

3. Eckstein, F. (2000). Phosphorothioate oligodeoxynucleotides: what is their origin and what is unique about them? Antisense and Nucleic Acid Drug Development, 10(2), 117-121.

4. Altmann, K. H., Fabbro, D., Dean, N. M., Geiger, T., Monia, B. P., Muller, M., et al. (1996). Second-generation antisense oligonucleotides: structure-activity relationships and the design of improved signal-transduction inhibitors. Biochemical Society Transactions, 24(3), 630-637.

5. Freier, S. M., \& Altmann, K. H. (1997). The ups and downs of nucleic acid duplex stability: structure-stability studies on chemically-modified DNA:RNA duplexes. Nucleic Acids Research, 25(22), 4429-4443.

6. ClinicalTrials.gov (2013) A study of the safety and efficacy of two different regimens of mipomersen in patients with familial hypercholesterolemia and inadequately controlled low-density lipoprotein cholesterol. http://clinicaltrials.gov/ct2/show/NCT01475825? term $=$ Focus + FH\&rank=1. Accessed 12 May 2013.

7. Jones, N. R., Pegues, M. A., McCrory, M. A., Singleton, W., Bethune, C., Baker, B. F., et al. (2012). A selective inhibitor of human C-reactive protein translation is efficacious in vitro and in C-reactive protein transgenic mice and humans. Molecular Therapy Nucleic Acids, 1, e52. doi:10.1038/mtna.2012.44.

8. McKay, R. A., Miraglia, L. J., Cummins, L. L., Owens, S. R., Sasmor, H., \& Dean, N. M. (1999). Characterization of a potent and specific class of antisense oligonucleotide inhibitor of human protein kinase $\mathrm{C}$-alpha expression. The Journal of Biological Chemistry, 274(3), 1715-1722.

9. Koller, E., Vincent, T. M., Chappell, A., De, S., Manoharan, M., \& Bennett, C. F. (2011). Mechanisms of single-stranded phosphorothioate modified antisense oligonucleotide accumulation in hepatocytes. Nucleic Acids Research, 39(11), 47954807. doi:10.1093/nar/gkr089.

10. Cossum, P. A., Truong, L., Owens, S. R., Markham, P. M., Shea, J. P., \& Crooke, S. T. (1994). Pharmacokinetics of a 14C-labeled phosphorothioate oligonucleotide, ISIS 2105, after intradermal administration to rats. The Journal of Pharmacology and Experimental Therapeutics, 269(1), 89-94.

11. Crooke, S. T., Graham, M. J., Zuckerman, J. E., Brooks, D., Conklin, B. S., Cummins, L. L., et al. (1996). Pharmacokinetic properties of several novel oligonucleotide analogs in mice. The Journal of Pharmacology and Experimental Therapeutics, 277(2), 923-937.
12. Levin, A. A., Yu, R. Z., \& Geary, R. S. (2008). Basic principles of the pharmacokinetics of antisense oligonucleotide drugs. In S. T. Crooke (Ed.), Antisense drug technology (2nd ed., pp. 183-216). Boca Raton: CRC.

13. Crooke, R. M., \& Graham, M. J. (2011). Therapeutic potential of antisense oligonucleotides for the management of dyslipidemia. Clinical Lipidology, 6, 675-692.

14. Elbashir, S. M., Harborth, J., Lendeckel, W., Yalcin, A., Weber, K., \& Tuschl, T. (2001). Duplexes of 21-nucleotide RNAs mediate RNA interference in cultured mammalian cells. Nature, 411(6836), 494-498. doi:10.1038/35078107.

15. Matranga, C., Tomari, Y., Shin, C., Bartel, D. P., \& Zamore, P. D. (2005). Passenger-strand cleavage facilitates assembly of siRNA into Ago2-containing RNAi enzyme complexes. Cell, 123(4), 607-620. doi:10.1016/j.cell.2005.08.044.

16. Kim, K., Lee, Y. S., \& Carthew, R. W. (2007). Conversion of preRISC to holo-RISC by Ago2 during assembly of RNAi complexes. $R N A, 13(1), 22-29$. doi:10.1261/rna.283207.

17. Gooding, M., Browne, L. P., Quinteiro, F. M., \& Selwood, D. L. (2012). siRNA delivery: from lipids to cell-penetrating peptides and their mimics. Chemical Biology and Drug Design, 80(6), 787-809. doi:10.1111/cbdd.12052.

18. Shyu, A. B., Wilkinson, M. F., \& van Hoof, A. (2008). Messenger RNA regulation: to translate or to degrade. The EMBO Journal, 27(3), 471-481. doi:10.1038/sj.emboj.7601977.

19. Esau, C. C., \& Monia, B. P. (2007). Therapeutic potential for microRNAs. Advanced Drug Delivery Reviews, 59(2-3), 101114. doi:10.1016/j.addr.2007.03.007.

20. Jaschinski, F., Rothhammer, T., Jachimczak, P., Seitz, C., Schneider, A., \& Schlingensiepen, K. H. (2011). The antisense oligonucleotide trabedersen (AP 12009) for the targeted inhibition of TGF-beta2. Current Pharmaceutical Biotechnology, 12(12), 2203-2213.

21. Karras, J. G., McKay, R. A., Lu, T., Pych, J., Frank, D. A., Rothstein, T. L., et al. (2000). STAT3 regulates the growth and immunoglobulin production of BCL(1) B cell lymphoma through control of cell cycle progression. Cellular Immunology, 202(2), 124-135. doi:10.1006/cimm.2000.1661.

22. Al-Asaaed, S., \& Winquist, E. (2013). Custirsen (OGX-011): clusterin inhibitor in metastatic prostate cancer. Current Oncology Reports, 15(2), 113-118. doi:10.1007/s11912-012-0285-1.

23. Janssen, H. L., Reesink, H. W., Lawitz, E. J., Zeuzem, S., Rodriguez-Torres, M., Patel, K., et al. (2013). Treatment of HCV infection by targeting microRNA. The New England Journal of Medicine. doi:10.1056/NEJMoa1209026.

24. Sloop, K. W., Cao, J. X., Siesky, A. M., Zhang, H. Y., Bodenmiller, D. M., Cox, A. L., et al. (2004). Hepatic and glucagon-like peptide1-mediated reversal of diabetes by glucagon receptor antisense oligonucleotide inhibitors. The Journal of Clinical Investigation, 113(11), 1571-1581. doi:10.1172/JCI20911.

25. Zinker, B. A., Rondinone, C. M., Trevillyan, J. M., Gum, R. J., Clampit, J. E., Waring, J. F., et al. (2002). PTP1B antisense oligonucleotide lowers PTP1B protein, normalizes blood glucose, and improves insulin sensitivity in diabetic mice. Proceedings of the National Academy of Sciences of the United States of America, 99(17), 11357-11362. doi:10.1073/pnas.142298199.

26. Hua, Y., Sahashi, K., Rigo, F., Hung, G., Horev, G., Bennett, C. F., et al. (2011). Peripheral SMN restoration is essential for long-term rescue of a severe spinal muscular atrophy mouse model. Nature, 478(7367), 123-126. doi:10.1038/nature10485.

27. Kordasiewicz, H. B., Stanek, L. M., Wancewicz, E. V., Mazur, C., McAlonis, M. M., Pytel, K. A., et al. (2012). Sustained therapeutic reversal of Huntington's disease by transient repression of huntingtin synthesis. Neuron, 74(6), 1031-1044. doi:10.1016/j. neuron.2012.05.009.

28. De Clercq, E. (2004). Antiviral drugs in current clinical use. Journal of Clinical Virology, 30(2), 115-133. doi:10.1016/j.jcv.2004.02.009. 
29. Hnik, P., Boyer, D. S., Grillone, L. R., Clement, J. G., Henry, S. P., $\&$ Green, E. A. (2009). Antisense oligonucleotide therapy in diabetic retinopathy. Journal of Diabetes Science and Technology, 3(4), 924-930.

30. Crooke, R., Baker, B. F., \& Wedel, M. K. (2007). Cardiovascular therapeutic applications. In S. T. Crooke (Ed.), Antisense drug technology: principles, strategies, and applications (2nd ed., pp. 601-639). Boca Raton: CRC.

31. Grundy, S. M. (2002). Low-density lipoprotein, non-high-density lipoprotein, and apolipoprotein B as targets of lipid-lowering therapy. Circulation, 106(20), 2526-2529.

32. Maningat, P., \& Breslow, J. L. (2011). Needed: pragmatic clinical trials for statin-intolerant patients. The New England Journal of Medicine, 365(24), 2250-2251. doi:10.1056/NEJMp1112023.

33. Austin, M. A., Hutter, C. M., Zimmern, R. L., \& Humphries, S. E. (2004). Genetic causes of monogenic heterozygous familial hypercholesterolemia: a HuGE prevalence review. American Journal of Epidemiology, 160(5), 407-420. doi:10.1093/aje/kwh236.

34. Raal, F. J., \& Santos, R. D. (2012). Homozygous familial hypercholesterolemia: current perspectives on diagnosis and treatment. Atherosclerosis, 223(2), 262-268. doi:10.1016/j.atherosclerosis. 2012.02.019.

35. Food and drug administration. http://www.accessdata.fda.gov/ drugsatfda_docs/label/2013/203568s000lbl.pdf (2013) Product label approved by the U.S. Food and Drug Association for Kynamro, NDA no. 203568. Accessed 10 May 2013.

36. Crooke, R. M., Graham, M. J., Lemonidis, K. M., Whipple, C. P., Koo, S., \& Perera, R. J. (2005). An apolipoprotein B antisense oligonucleotide lowers LDL cholesterol in hyperlipidemic mice without causing hepatic steatosis. Journal of Lipid Research, 46(5), 872-884.

37. Mullick, A. E., Fu, W., Graham, M. J., Lee, R. G., Witchell, D., Bell, T. A., et al. (2011). Antisense oligonucleotide reduction of apoBameliorated atherosclerosis in LDL receptor-deficient mice. Journal of Lipid Research, 52(5), 885-896. doi:10.1194/jlr.M011791.

38. Lee, R. G., Fu, W., Graham, M. J., Mullick, A. E., Sipe, D., Gattis, D., et al. (2013). Comparison of the pharmacological profiles of murine antisense oligonucleotides targeting apolipoprotein B and microsomal triglyceride transfer protein. Journal of Lipid Research, 54(3), 602-614. doi:10.1194/jlr.M029215.

39. Lin, X., Schonfeld, G., Yue, P., \& Chen, Z. (2002). Hepatic fatty acid synthesis is suppressed in mice with fatty livers due to targeted apolipoprotein B38.9 mutation. Arteriosclerosis, Thrombosis, and Vascular Biology, 22(3), 476-482.

40. Kastelein, J. J., Wedel, M. K., Baker, B. F., Su, J., Bradley, J. D., Yu, R. Z., et al. (2006). Potent reduction of apolipoprotein B and low-density lipoprotein cholesterol by short-term administration of an antisense inhibitor of apolipoprotein B. Circulation, 114(16), $1729-1735$.

41. Yu, R. Z., Geary, R. S., Flaim, J. D., Riley, G. C., Tribble, D. L., vanVliet, A. A., et al. (2009). Lack of pharmacokinetic interaction of mipomersen sodium (ISIS 301012), a 2'-O-methoxyethyl modified antisense oligonucleotide targeting apolipoprotein B-100 messenger RNA, with simvastatin and ezetimibe. Clinical Pharmacokinetics, 48(1), 39-50. doi:10.2165/0003088-200948010-00003.

42. Akdim, F., Tribble, D. L., Flaim, J. D., Yu, R., Su, J., Geary, R. S., et al. (2011). Efficacy of apolipoprotein B synthesis inhibition in subjects with mild-to-moderate hyperlipidaemia. European Heart Journal, 32(21), 2650-2659. doi:10.1093/eurheartj/ehr148.

43. Akdim, F., Stroes, E. S., Sijbrands, E. J., Tribble, D. L., Trip, M. D., Jukema, J. W., et al. (2010). Efficacy and safety of mipomersen, an antisense inhibitor of apolipoprotein B, in hypercholesterolemic subjects receiving stable statin therapy. Journal of the American College of Cardiology, 55(15), 1611-1618. doi:10.1016/j.jacc.2009.

44. Akdim, F., Visser, M. E., Tribble, D. L., Baker, B. F., Stroes, E. S., Yu, R., et al. (2010). Effect of mipomersen, an apolipoprotein B synthesis inhibitor, on low-density lipoprotein cholesterol in patients with familial hypercholesterolemia. The American Journal of Cardiology, 105(10), 1413-1419. doi:10.1016/j.amjcard.2010.01.003.

45. Alonso-Ruiz, A., Pijoan, J. I., Ansuategui, E., Urkaregi, A., Calabozo, M., \& Quintana, A. (2008). Tumor necrosis factor alpha drugs in rheumatoid arthritis: systematic review and metaanalysis of efficacy and safety. BMC Musculoskeletal Disorders, 9, 52. doi:10.1186/1471-2474-9-52.

46. Mertens, M., \& Singh, J. A. (2009). Anakinra for rheumatoid arthritis: a systematic review. The Journal of Rheumatology, 36(6), 1118-1125. doi:10.3899/jrheum.090074.

47. Scheinfeld, N. (2005). Adalimumab: a review of side effects. Expert Opinion on Drug Safety, 4(4), 637-641. doi:10.1517/14740338.4.4. 637.

48. Raal, F. J., Santos, R. D., Blom, D. J., Marais, A. D., Charng, M. J., Cromwell, W. C., et al. (2010). Mipomersen, an apolipoprotein B synthesis inhibitor, for lowering of LDL cholesterol concentrations in patients with homozygous familial hypercholesterolaemia: a randomised, double-blind, placebo-controlled trial. The Lancet, 375(9719), 998-1006. doi:10.1016/S0140-6736(10)60284-X.

49. Stein, E. A., Dufour, R., Gagne, C., Gaudet, D., East, C., Donovan, J. M., et al. (2012). Apolipoprotein B synthesis inhibition with mipomersen in heterozygous familial hypercholesterolemia: results of a randomized, double-blind, placebo-controlled trial to assess efficacy and safety as add-on therapy in patients with coronary artery disease. Circulation, 126(19), 2283-2292. doi:10. 1161/CIRCULATIONAHA.112.104125.

50. McGowan, M. P., Tardif, J. C., Ceska, R., Burgess, L. J., Soran, H., Gouni-Berthold, I., et al. (2012). Randomized, placebocontrolled trial of mipomersen in patients with severe hypercholesterolemia receiving maximally tolerated lipid-lowering therapy. PLoS One, 7(11), e49006. doi:10.1371/journal.pone.0049006.

51. Visser, M. E., Wagener, G., Baker, B. F., Geary, R. S., Donovan, J. M., Beuers, U. H., et al. (2012). Mipomersen, an apolipoprotein B synthesis inhibitor, lowers low-density lipoprotein cholesterol in high-risk statin-intolerant patients: a randomized, double-blind, placebo-controlled trial. European Heart Journal, 33(9), 11421149. doi:10.1093/eurheartj/ehs023.

52. Cromwell, W. C., Thomas, G. S., Boltje, I., Chin, W., \& Davidson, M. (2011). Safety and efficacy of mipomersen administered as add-on therapy in patients with hypercholesterolemia and high cardiovascular risk. Journal of the American College of Cardiology, 57(14), E504.

53. Duell, P. B., Santos, R. D., East, C., Guyton, J. R., Moriarty, P. M., Donovan, J. M., et al. (2012). Long-term safety and efficacy of mipomersen in patients with familial hypercholesterolemia uncontrolled by maximally tolerated lipid lowering therapy. Journal of Clinical Lipidology, 6(3), 291.

54. Zimmermann, T. S., Lee, A. C., Akinc, A., Bramlage, B., Bumcrot, D., Fedoruk, M. N., et al. (2006). RNAi-mediated gene silencing in non-human primates. Nature, 441(7089), 111-114. doi:10.1038/nature04688.

55. Straarup, E. M., Fisker, N., Hedtjarn, M., Lindholm, M. W., Rosenbohm, C., Aarup, V., et al. (2010). Short locked nucleic acid antisense oligonucleotides potently reduce apolipoprotein B mRNA and serum cholesterol in mice and non-human primates. Nucleic Acids Research, 38(20), 7100-7111. doi:10.1093/nar/gkq457.

56. ClinicalTrials.gov (2013) Multiple ascending dose study of SPC4955 in healthy subjects. http://clinicaltrials.gov/ct2/show/ NCT01365663?term=SPC4955\&rank=1. Accessed 12 May 2013.

57. Grundy, S. M., Cleeman, J. I., Merz, C. N., Brewer, H. B., Jr., Clark, L. T., Hunninghake, D. B., et al. (2004). Implications of recent clinical trials for the National Cholesterol Education Program Adult Treatment Panel III guidelines. Circulation, 110(2), 227-239. doi:10.1161/01.CIR.0000133317.49796.0E.

58. Ewald, N., \& Kloer, H. U. (2009). Severe hypertriglyceridemia: an indication for apheresis? Atherosclerosis Supplements, 10(5), 4952. doi:10.1016/S1567-5688(09)71810-0. 
59. Tsuang, W., Navaneethan, U., Ruiz, L., Palascak, J. B., \& Gelrud, A. (2009). Hypertriglyceridemic pancreatitis: presentation and management. The American Journal of Gastroenterology, 104(4), 984-991. doi:10.1038/ajg.2009.27.

60. Christian, J. B., Arondekar, B., Buysman, E. K., Johnson, S. L., Seeger, J. D., \& Jacobson, T. A. (2012). Clinical and economic benefits observed when follow-up triglyceride levels are less than $500 \mathrm{mg} / \mathrm{dL}$ in patients with severe hypertriglyceridemia. Journal of Clinical Lipidology, 6(5), 450-461. doi:10.1016/j.jacl.2012.08.007.

61. ClinicalTrials.gov (2013) A randomized, double-blind, placebocontrolled, dose response, Phase 2 study of ISIS 304801 administered subcutaneously to patients with severe or uncontrolled hypertriglyceridemia. http://www.clinicaltrials.gov/ct2/show/NCT01529424?term= apoC-III\&rank=1. Accessed 12 May 2013.

62. Gotto, A. M., Jr., Pownall, H. J., \& Havel, R. J. (1986). Introduction to the plasma lipoproteins. Methods in Enzymology, 128, 3-41.

63. Ito, Y., Azrolan, N., O'Connell, A., Walsh, A., \& Breslow, J. L. (1990). Hypertriglyceridemia as a result of human apo CIII gene expression in transgenic mice. Science, 249(4970), 790-793.

64. Lee, H. Y., Birkenfeld, A. L., Jornayvaz, F. R., Jurczak, M. J., Kanda, S., Popov, V., et al. (2011). Apolipoprotein CIII overexpressing mice are predisposed to diet-induced hepatic steatosis and hepatic insulin resistance. Hepatology, 54(5), 1650-1660. doi:10.1002/hep.24571.

65. Jong, M. C., Rensen, P. C., Dahlmans, V. E., van der Boom, H., van Berkel, T. J., \& Havekes, L. M. (2001). Apolipoprotein C-III deficiency accelerates triglyceride hydrolysis by lipoprotein lipase in wild-type and apoE knockout mice. Journal of Lipid Research, 42(10), 1578-1585.

66. Duivenvoorden, I., Teusink, B., Rensen, P. C., Romijn, J. A., Havekes, L. M., \& Voshol, P. J. (2005). Apolipoprotein C3 deficiency results in diet-induced obesity and aggravated insulin resistance in mice. Diabetes, 54(3), 664-671.

67. Pollin, T. I., Damcott, C. M., Shen, H., Ott, S. H., Shelton, J., Horenstein, R. B., et al. (2008). A null mutation in human APOC3 confers a favorable plasma lipid profile and apparent cardioprotection. Science, 322(5908), 1702-1705. doi:10.1126/science.1161524.

68. Petersen, K. F., Dufour, S., Hariri, A., Nelson-Williams, C., Foo, J. N., Zhang, X. M., et al. (2010). Apolipoprotein C3 gene variants in nonalcoholic fatty liver disease. The New England Journal of Medicine, 362(12), 1082-1089. doi:10.1056/NEJMoa0907295.

69. Wang, C. S., McConathy, W. J., Kloer, H. U., \& Alaupovic, P. (1985). Modulation of lipoprotein lipase activity by apolipoproteins. Effect of apolipoprotein C-III. J Clin Invest, 75(2), 384-390. doi:10.1172/JCI111711.

70. Mendivil, C. O., Zheng, C., Furtado, J., Lel, J., \& Sacks, F. M. (2010). Metabolism of very-low-density lipoprotein and lowdensity lipoprotein containing apolipoprotein C-III and not other small apolipoproteins. Arteriosclerosis, Thrombosis, and Vascular Biology, 30(2), 239-245. doi:10.1161/ATVBAHA.109.197830.

71. Sundaram, M., Zhong, S., Bou Khalil, M., Links, P. H., Zhao, Y., Iqbal, J., et al. (2010). Expression of apolipoprotein C-III in McARH7777 cells enhances VLDL assembly and secretion under lipid-rich conditions. Journal of Lipid Research, 51(1), 150-161. doi:10.1194/M900346-JLR200.

72. Sacks, F. M., Alaupovic, P., Moye, L. A., Cole, T. G., Sussex, B., Stampfer, M. J., et al. (2000). VLDL, apolipoproteins B, CIII, and $\mathrm{E}$, and risk of recurrent coronary events in the Cholesterol and Recurrent Events (CARE) trial. Circulation, 102(16), 1886-1892.

73. Kawakami, A., Aikawa, M., Libby, P., Alcaide, P., Luscinskas, F. W., \& Sacks, F. M. (2006). Apolipoprotein CIII in apolipoprotein $\mathrm{B}$ lipoproteins enhances the adhesion of human monocytic cells to endothelial cells. Circulation, 113(5), 691-700. doi:10.1161/ CIRCULATIONAHA.105.591743.

74. Kawakami, A., Aikawa, M., Alcaide, P., Luscinskas, F. W., Libby, P., \& Sacks, F. M. (2006). Apolipoprotein CIII induces expression of vascular cell adhesion molecule-1 in vascular endothelial cells and increases adhesion of monocytic cells. Circulation, 114(7), 681-687. doi:10.1161/CIRCULATIONAHA.106.622514.

75. Chen, M., Breslow, J. L., Li, W., \& Leff, T. (1994). Transcriptional regulation of the apoC-III gene by insulin in diabetic mice: correlation with changes in plasma triglyceride levels. Journal of Lipid Research, 35(11), 1918-1924.

76. Altomonte, J., Cong, L., Harbaran, S., Richter, A., Xu, J., Meseck, M., et al. (2004). Foxo1 mediates insulin action on apoC-III and triglyceride metabolism. The Journal of Clinical Investigation, 114(10), 1493-1503. doi:10.1172/JCI19992.

77. Kozlitina, J., Boerwinkle, E., Cohen, J. C., \& Hobbs, H. H. (2011). Dissociation between APOC3 variants, hepatic triglyceride content and insulin resistance. Hepatology, 53(2), 467-474. doi:10.1002/hep.24072.

78. Atzmon, G., Rincon, M., Schechter, C. B., Shuldiner, A. R., Lipton, R. B., Bergman, A., et al. (2006). Lipoprotein genotype and conserved pathway for exceptional longevity in humans. PLoS Biology, 4(4), e113. doi:10.1371/journal.pbio.0040113.

79. Graham, M. J., Lee, R. G., Bell, T. A., 3rd, Fu, W., Mullick, A. E., Alexander, V. J., et al. (2013). Antisense oligonucleotide inhibition of apolipoprotein C-III reduces plasma triglycerides in rodents, nonhuman primates, and humans. Circulation Research. doi:10.1161/CIRCRESAHA.111.300367.

80. Millar, J. S., Cromley, D. A., McCoy, M. G., Rader, D. J., \& Billheimer, J. T. (2005). Determining hepatic triglyceride production in mice: comparison of poloxamer 407 with Triton WR-1339. Journal of Lipid Research, 46(9), 2023-2028. doi:10.1194/jlr.D500019-JLR200.

81. ClinicalTrials.gov (2013) A randomized, double blind, placebocontrolled, Phase 2 study to investigate the effects of ISIS 304801 lowering of ISIS-APOCIIIRX on triglyceride levels and insulin sensitivity in subjects with type 2 diabetes mellitus. http://www. clinicaltrials.gov/ct2/show/NCT01647308?term=apoC-III\&rank=3. Accessed 12 May 2013.

82. Asakai, R., Chung, D. W., Davie, E. W., \& Seligsohn, U. (1991). Factor XI deficiency in Ashkenazi Jews in Israel. The New England Journal of Medicine, 325(3), 153-158. doi:10.1056/NEJM199107183250303.

83. Gailani, D., \& Renne, T. (2007). The intrinsic pathway of coagulation: a target for treating thromboembolic disease? Journal of Thrombosis and Haemostasis, 5(6), 1106-1112. doi:10.1111/j. 1538-7836.2007.02446.x.

84. Meijers, J. C., Tekelenburg, W. L., Bouma, B. N., Bertina, R. M., \& Rosendaal, F. R. (2000). High levels of coagulation factor XI as a risk factor for venous thrombosis. The New England Journal of Medicine, 342(10), 696-701. doi:10.1056/NEJM200003093421004.

85. Yang, D. T., Flanders, M. M., Kim, H., \& Rodgers, G. M. (2006). Elevated factor XI activity levels are associated with an increased odds ratio for cerebrovascular events. American Journal of Clinical Pathology, 126(3), 411-415. doi:10.1309/QC259F09UNMKVP0R.

86. Rosen, E. D., Gailani, D., \& Castellino, F. J. (2002). FXI is essential for thrombus formation following $\mathrm{FeCl} 3$-induced injury of the carotid artery in the mouse. Thrombosis and Haemostasis, 87(4), 774-776.

87. Cheng, Q., Tucker, E. I., Pine, M. S., Sisler, I., Matafonov, A., Sun, M. F., et al. (2010). A role for factor XIIa-mediated factor XI activation in thrombus formation in vivo. Blood, 116(19), 39813989. doi:10.1182/blood-2010-02-270918.

88. Tucker, E. I., Marzec, U. M., White, T. C., Hurst, S., Rugonyi, S., McCarty, O. J., et al. (2009). Prevention of vascular graft occlusion and thrombus-associated thrombin generation by inhibition of factor XI. Blood, 113(4), 936-944. doi:10.1182/blood-2008-06-163675.

89. Gruber, A., \& Hanson, S. R. (2003). Factor XI-dependence of surface- and tissue factor-initiated thrombus propagation in primates. Blood, 102(3), 953-955. doi:10.1182/blood-2003-01-0324.

90. Wang, X., Smith, P. L., Hsu, M. Y., Gailani, D., Schumacher, W. A., Ogletree, M. L., et al. (2006). Effects of factor XI deficiency 
on ferric chloride-induced vena cava thrombosis in mice. Journal of Thrombosis and Haemostasis, 4(9), 1982-1988. doi:10.1111/j. 1538-7836.2006.02093.x.

91. Yamashita, A., Nishihira, K., Kitazawa, T., Yoshihashi, K., Soeda, T., Esaki, K., et al. (2006). Factor XI contributes to thrombus propagation on injured neointima of the rabbit iliac artery. Journal of Thrombosis and Haemostasis, 4(7), 1496-1501. doi:10.1111/j.1538-7836.2006.01973.x.

92. Zhang, H., Lowenberg, E. C., Crosby, J. R., MacLeod, A. R., Zhao, C., Gao, D., et al. (2010). Inhibition of the intrinsic coagulation pathway factor XI by antisense oligonucleotides: a novel antithrombotic strategy with lowered bleeding risk. Blood, 116(22), 4684-4692. doi:10.1182/blood-2010-04-277798.

93. Younis, H. S., Crosby, J., Huh, J. I., Lee, H. S., Rime, S., Monia, B., et al. (2012). Antisense inhibition of coagulation factor XI prolongs APTT without increased bleeding risk in cynomolgus monkeys. Blood. doi:10.1182/blood-2011-10-387134.

94. Crosby, J. R., Marzec, U., Revenko, A. S., Zhao, C., Gao, D., Matafonov, A., et al. (2013). Antithrombotic effect of antisense factor XI oligonucleotide treatment in primates. Arteriosclerosis, Thrombosis, and Vascular Biology, 33(7), 1670-1678. doi:10. 1161/ATVBAHA.113.301282.

95. Liu Q, Bethune C, Dessouki E, Grundy J, Monia B, Bhanot S

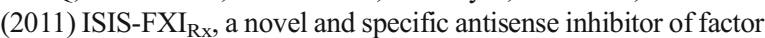
$\mathrm{XI}$, caused significant reduction in FXI antigen and activity and increased aPTT without causing bleeding in healthy volunteers. Paper presented at the 53rd American Society of Hematology annual meeting and exposition, San Diego, California

96. Rashid, S., Curtis, D. E., Garuti, R., Anderson, N. N., Bashmakov, Y., Ho, Y. K., et al. (2005). Decreased plasma cholesterol and hypersensitivity to statins in mice lacking Pcsk9. Proceedings of the National Academy of Sciences of the United States of America, 102(15), 5374-5379. doi:10.1073/pnas.0501652102.

97. Kowal, R. C., Herz, J., Weisgraber, K. H., Mahley, R. W., Brown, M. S., \& Goldstein, J. L. (1990). Opposing effects of apolipoproteins $\mathrm{E}$ and $\mathrm{C}$ on lipoprotein binding to low density lipoprotein receptor-related protein. The Journal of Biological Chemistry, 265(18), 10771-10779.

98. Cohen, J. C., Boerwinkle, E., Mosley, T. H., Jr., \& Hobbs, H. H. (2006). Sequence variations in PCSK9, low LDL, and protection against coronary heart disease. The New England Journal of Medicine, 354(12), 1264-1272. doi:10.1056/NEJMoa054013.

99. Zhang, D. W., Lagace, T. A., Garuti, R., Zhao, Z., McDonald, M., Horton, J. D., et al. (2007). Binding of proprotein convertase subtilisin/kexin type 9 to epidermal growth factor-like repeat A of low density lipoprotein receptor decreases receptor recycling and increases degradation. The Journal of Biological Chemistry, 282(25), 18602-18612. doi:10.1074/jbc.M702027200.

100. Graham, M. J., Lemonidis, K. M., Whipple, C. P., Subramaniam, A., Monia, B. P., Crooke, S. T., et al. (2007). Antisense inhibition of proprotein convertase subtilisin/kexin type 9 reduces serum LDL in hyperlipidemic mice. Journal of Lipid Research, 48(4), 763-767. doi:10.1194/jlr.C600025-JLR200.

101. Roden, M., Krssak, M., Stingl, H., Gruber, S., Hofer, A., Furnsinn, C., et al. (1999). Rapid impairment of skeletal muscle glucose transport/phosphorylation by free fatty acids in humans. Diabetes, 48(2), 358-364.

102. Gupta, N., Fisker, N., Asselin, M. C., Lindholm, M., Rosenbohm, C., Orum, H., et al. (2010). A locked nucleic acid antisense oligonucleotide (LNA) silences PCSK9 and enhances LDLR expression in vitro and in vivo. PLoS One, 5(5), e10682. doi:10. 1371/journal.pone.0010682.

103. Greco, A. V., Mingrone, G., Giancaterini, A., Manco, M., Morroni, M., Cinti, S., et al. (2002). Insulin resistance in morbid obesity: reversal with intramyocellular fat depletion. Diabetes, 51(1), 144-151.

104. van Poelgeest, E. P., Swart, R. M., Betjes, M. G., Moerland, M., Weening, J. J., Tessier, Y., et al. (2013). Acute kidney injury during therapy with an antisense oligonucleotide directed against PCSK9. American Journal of Kidney Diseases. doi:10.1053/j.ajkd.2013.02. 359.

105. Frank-Kamenetsky, M., Grefhorst, A., Anderson, N. N., Racie, T. S., Bramlage, B., Akinc, A., et al. (2008). Therapeutic RNAi targeting PCSK9 acutely lowers plasma cholesterol in rodents and LDL cholesterol in nonhuman primates. Proceedings of the National Academy of Sciences of the United States of America, 105(33), 11915-11920. doi:10.1073/pnas.0805434105.

106. Girousse, A., Tavernier, G., Valle, C., Moro, C., Mejhert, N., Dinel, A. L., et al. (2013). Partial inhibition of adipose tissue lipolysis improves glucose metabolism and insulin sensitivity without alteration of fat mass. PLoS Biology, 11(2), e1001485. doi:10.1371/journal.pbio.1001485.

107. McLean, J. W., Tomlinson, J. E., Kuang, W. J., Eaton, D. L., Chen, E. Y., Fless, G. M., et al. (1987). cDNA sequence of human apolipoprotein(a) is homologous to plasminogen. Nature, 330(6144), 132-137. doi:10.1038/330132a0.

108. Erqou, S., Thompson, A., Di Angelantonio, E., Saleheen, D., Kaptoge, S., Marcovina, S., et al. (2010). Apolipoprotein(a) isoforms and the risk of vascular disease: systematic review of 40 studies involving 58,000 participants. Journal of the American College of Cardiology, 55(19), 2160-2167. doi:10.1016/j.jacc. 2009.10.080.

109. Erqou, S., Kaptoge, S., Perry, P. L., Di Angelantonio, E., Thompson, A., White, I. R., et al. (2009). Lipoprotein(a) concentration and the risk of coronary heart disease, stroke, and nonvascular mortality. JAMA : The Journal of the American Medical Association, 302(4), 412-423. doi:10.1001/jama.2009.1063.

110. Thanassoulis, G., Campbell, C. Y., Owens, D. S., Smith, J. G., Smith, A. V., Peloso, G. M., et al. (2013). Genetic associations with valvular calcification and aortic stenosis. The New England Journal of Medicine, 368(6), 503-512. doi:10.1056/NEJMoa1109034.

111. Dube, J. B., Boffa, M. B., Hegele, R. A., \& Koschinsky, M. L. (2012). Lipoprotein(a): more interesting than ever after 50 years. Current Opinion in Lipidology, 23(2), 133-140. doi:10.1097/ MOL.0b013e32835111d8.

112. Koschinsky, M. L., \& Marcovina, S. M. (2004). Structurefunction relationships in apolipoprotein(a): insights into lipoprotein(a) assembly and pathogenicity. Current Opinion in Lipidology, 15(2), 167-174.

113. Bergmark, C., Dewan, A., Orsoni, A., Merki, E., Miller, E. R., Shin, M. J., et al. (2008). A novel function of lipoprotein [a] as a preferential carrier of oxidized phospholipids in human plasma. Journal of Lipid Research, 49(10), 2230-2239. doi:10.1194/jlr. M800174-JLR200.

114. Merki, E., Graham, M., Taleb, A., Leibundgut, G., Yang, X., Miller, E. R., et al. (2011). Antisense oligonucleotide lowers plasma levels of apolipoprotein (a) and lipoprotein (a) in transgenic mice. Journal of the American College of Cardiology, 57(15), 1611-1621. doi:10.1016/j.jacc.2010.10.052. 